\title{
The Effect of Language Differences and National Culture on Operational Process \\ Compliance
}

John V. Gray

Fisher College of Business, Ohio State University, Columbus, Ohio, USA

\section{Brett Massimino}

School of Hotel Administration, Cornell University, Ithaca, New York, USA

\section{KEYWORDS}

routines; knowledge transfer; offshoring; international; manufacturing

\begin{abstract}
With increasing frequency, firms are locating their operations in disparate countries with distinct national cultures and languages. This study develops and empirically tests hypotheses relating an operation's process compliance performance to (1) the presence of a language difference between the location of the operation and that of headquarters and (2) the national culture of the location of the operation and that of headquarters. Employing an international sample of pharmaceutical manufacturing plants located primarily in Western nations, the analysis reveals that a language difference between the location of a plant and the firm's headquarters is consistently related to decreased process compliance at the plant level. Regarding national culture, only limited evidence of a direct relationship between national cultural dimensions (at either the plant or headquarters location) and process compliance exists. However, the analysis does suggest that cultural congruence between the location of the plant and that of headquarters can relate to improved compliance performance. Such a relationship depends on the specific national cultural dimension studied. While these results are obtained in a specific manufacturing setting, they potentially have implications for process compliance in any global operation.
\end{abstract}




\section{INTRODUCTION}

Multinational organizations have long established global operations (Ferdows 1997, Skinner 1964) for many reasons, including lower input costs, access to resources, lower taxes, and the avoidance of tariffs (Chung and Alcácer 2002, Davidson 1980, Rugman and Verbeke 2001). However, the management of international operations is fraught with challenges (Ellram et al. 2008, Ferdows 2006, Skinner 1964). Firms often struggle to align operational capabilities with corporate objectives (Hayes and Wheelwright 1984, Skinner 1969), and locating operations in distant countries can increase these struggles (Klassen and Whybark 1994). An operational capability that has received little attention in this regard is process compliance, which is defined as consistent adherence to operational routines such as standard operating procedures, good manufacturing practices (GMPs), and governmental regulations (Anand et al. 2012). Success in ensuring high levels of process compliance is a necessary precursor to the improvement of other operational performance dimensions (Ferdows and DeMeyer 1990, Rosenzweig and Roth 2004), and failure to ensure proper compliance can have substantial consequences. However, the implications of process compliance performance are often overlooked when making location decisions (Accenture 2011), perhaps because it is assumed that such performance can be easily attained.

A recent study (Gray et al. 2011) suggested that process compliance indeed suffers as a result of conducting operations in an offshore location. Specifically, the authors found significantly higher process compliance levels for the mainland US pharmaceutical plants of US-based multinationals, when compared to the offshore (Puerto Rican) plants of these same firms. Since the study involved only one high-wage headquarters (HQ) location (the United States) and one low-wage offshore location (Puerto Rico), alternative explanations remained. The current study extends previous work by employing a global sample involving 8501 process compliance outcomes for 1554 plants in 34 countries. As a result, the findings from Gray et al. (2011) can be generalized to high-wage plant locations, the effects of language and national culture can be disentangled, and the nuanced effects of national culture at the level of individual cultural dimensions can be examined. Specifically, in this study, we ask the following 
questions: (1) Does a language difference between the HQ location and the location of the operation relate to decreased process compliance? (2) Are the cultural attributes of either of these locations directly related to process compliance? If so, which attributes? (3) Does congruence between the HQ location and that of the operation in terms of cultural attributes relate to improved process compliance? The setting for this research is manufacturing, but the importance of process compliance extends to other settings such as accounting (Ettredge et al. 2011), information technology (Puhakainen and Siponen 2010), and healthcare (Pronovost and Vohr 2010).

The analyses herein reveal consistent evidence that a difference in national language as well as differences along at least one cultural dimension relate to decreased plant-level process compliance. The detrimental effects of a language difference persist in a subsample of plants located exclusively in the mainland United States, indicating that a language difference can indeed pose a challenge, even when offshoring work to high-wage locations. Of note, only inconsistent evidence of a direct relationship between individual national cultural dimensions and process compliance is found, implying that challenges introduced by a language difference tend to dominate those related to national culture.

\section{HYPOTHESIS DEVELOPMENT}

The development of hypotheses for this research relies on the following assumptions: (1) Each firm has a single HQ in a single geographic location, (2) each plant produces the company's products, and is expected to operate at legally required levels of process compliance, and (3) each HQ retains unique knowledge related to achieving this goal (e.g., through corporate quality or engineering functions). Based on the assumptions above, high levels of process compliance would require the HQ to transfer some knowledge to its plant locations. The most commonly adopted conceptual model of intra-organizational knowledge transfer, the sender-receiver model (Noorderhaven and Harzing 2009), is employed to develop the hypotheses. Specifically, the firm's HQ is treated as the knowledge sender and each plant as a 
knowledge receiver throughout hypothesis development. As each plant is wholly owned by the firm, we can assume that "both the sender and receiver of the know-how are ... rewarded for effective knowledge transfer and not for cheating each other as in a market setting” (Hennart 2009, p. 134).

Following Anand et al. (2012), process compliance is defined as consistent adherence to “routines-as-targets” (Nelson and Winter 1982, p. 113). Routines-as-targets are routines intended to be stable, although they can be modified through a change management routine (Anand et al. 2012). Routines can be broken down into performative, ostensive, and artifact components (Pentland and Feldman 2005). The definitions of each of these, along with operational examples in the empirical setting of this study, are provided in Table 1. In the context of this study, knowledge receivers (plants) are responsible for the performative component, knowledge senders (HQs) possess the majority of knowledge regarding the relevant ostensive components, and both parties aid in the development of the artifacts. Using these terms from the routines literature, process compliance could then be considered the extent to which the performative aspects are consistent with the ostensive aspects.

\subsection{Language Difference and Process Compliance}

Under a sender-receiver model, communication between parties follows three basic steps (Shannon and Weaver 1949): (1) the source — the knowledge sender — encodes an abstract idea or phenomenon into a message appropriate for transmission through a chosen medium, (2) this message is exchanged with the recipient—-the knowledge receiver—-through the chosen medium, and (3) the recipient decodes and internalizes the message. Below, the assertion is first made that a language difference will disrupt knowledge transfer. Then, the mechanisms by which such a disruption inhibits process compliance performance at the plant are described.

It is intuitive that a language difference between parties will disrupt communications and knowledge transfer (Welch and Welch 2008). Four archetypical approaches to dealing with this disruption 
exist, none of which completely resolves the challenge. One is to translate all communication to the language of the recipient (Nida and Tabr 2003). This can be less than fully effective due to basic translation errors, but also because translated words can take on different meanings in terms of what they reference (Joseph 1995, Saussure 2011). It has been argued that a perfect translation is impossible (Bassnett 2002), and "translators live with the constant guilt of knowing that they can never render the text faithfully in another language” (Joseph 1995, p. 14). A second approach to resolving a language difference is to employ intermediaries for communication between organizational units (MarschanPiekkari et al. 1999). Intermediaries not only add another iteration of knowledge transfer between the original source and ultimate recipient, but they also can (intentionally or unintentionally) distort the knowledge being transferred and/or act as a gatekeeper in the transmission process (Janssens et al. 2004, Marschan-Piekkari et al. 1999, Welch and Welch 2008). The use of intermediaries can also reduce the level of direct contact that workers from either unit (HQ or the plant in this context) have with one another (Marschan-Piekkari et al. 1999), reducing informal and social knowledge exchanges which are important to successful knowledge transfers (Reagans and McEvily 2003). A third approach is to employ a lingua franca, or common language mandate, to ensure that a single language is used for intraorganizational communications (Crystal 2003). Doing so may force non-native speakers to converse in a language in which they are not proficient and which is inconsistent with their internal thought processes (Fixman 1990, Sapir 1929, Varonis and Gass 1985). A lingua franca mandate may also cause non-native speakers to experience a loss in status or social standing (Neeley 2013), thereby increasing the difficulty in transferring knowledge to alienated organizations (Szulanski 1996). A fourth approach involves employing numerical metrics as "the levers through which manufacturing operations are controlled” (Bendoly et al. 2007, p. 271). While numerical metrics may be less subject to misinterpretation due to language differences, written or oral communication is still necessary to ensure that the metrics are accurately measured. Such communications will also be necessary to address any deviations from the desired metric. In addition, no set of numerical metrics can encompass all the requirements of process compliance (Melnyk et al. 2004). Taken together, firms have used various approaches to traverse a 
language difference, but none can consistently achieve the level of efficacy in knowledge transfers that can be achieved when no language barrier exists.

To achieve process compliance, the performative aspects of the receiver's routine must match the ostensive aspects of the sender's routine. A language difference can hinder this in two ways. First, the knowledge sender needs to communicate the ostensive aspects, either orally or through written artifacts. A language difference will directly hinder the translation of written procedures from the sender's language to the receiver's. A greater challenge involves translating the often vague and abstract ostensive components (Feldman and Pentland 2003, Pentland and Feldman 2005), which are fundamentally tacit (Polanyi 1966) and therefore difficult to transfer (Szulanski 2000). Second, the knowledge receiver must execute the routine as intended on a day-to-day basis. Lack of clarity in artifacts due to translation challenges directly affects this process. Furthermore, any monitoring and feedback systems implemented in the presence of a language difference are likely to omit or misinterpret the subjective assessments predicated on linguistic communications, ultimately making the systems less effective. In sum, a plantHQ language difference will relate to reduced process compliance at the plant. Formally:

Hypothesis 1. (H1): A language difference between an organization's knowledge sender (HQ) and receiver (manufacturing plant) is negatively associated with the knowledge receiver's level of process compliance.

\subsection{Direct Relationships between National Cultural Attributes and Process Compliance}

The next set of hypotheses relates to specific national cultural attributes at the knowledge sender and receiver locations. Hofstede's (2001) framework for characterizing national cultures was adopted, as this framework is the most commonly used in the literature, provides a parsimonious and testable specification of national cultures, and lays the foundation for other cultural characterization frameworks, such as that of House et al. (2004). According to the Hofstede (2001) framework, five dimensions classify 
cultures at the national level of analysis. These dimensions have been argued to provide a rich description of the pattern of basic assumptions that constitute a culture and have been utilized in a variety of managerial disciplines (Giannetti and Yafeh 2011, Weber et al. 1996). Hypotheses are offered for four of these dimensions: uncertainty avoidance (UAI), long-term orientation (LTO), power distance (PDI), and individualism (IDV). Hypotheses for the final Hofstede (2001) dimension (masculinity) are not presented, as it was determined prior to analyzing any data that no logical conceptual linkage existed between this dimension and process compliance. An exploratory analysis on this dimension revealed that, as expected, there was no statistically significant relationship between the masculinity dimensions and process compliance performance.

\subsubsection{Uncertainty Avoidance}

The UAI dimension of a culture relates to individuals' tendencies to actively seek the elimination of uncertain outcomes. These characteristics are strongly aligned with the fundamental premises of operating with high levels of process compliance-process control and variation reduction. At the knowledge-receiver level, individuals desiring to avoid uncertainty will naturally be uncomfortable when deviating from the formal operating procedures and rules embodied by the artifacts being transferred. Furthermore, individuals high in UAI will actively seek to resolve any ambiguity related to non-codified aspects of the ostensive routine. On average, this should relate to higher levels of process compliance:

Hypothesis 2a. (H2a): UAI levels at the knowledge-receiver location are positively associated with the knowledge receiver's level of process compliance.

At the knowledge-sender level, a high level of UAI relates to an aversion to uncertainty about the knowledge receiver's behaviors. Such aversion leads the knowledge sender to implement robust monitoring and enforcement systems and ensure that artifacts are fully internalized by the receiver. Furthermore, senders high in UAI are naturally inclined to create detailed and easy-to-follow artifacts so 
that the uncertainty associated with non-codified aspects of the ostensive routine is minimized. These attributes serve to reduce the gap between performative and ostensive components of the routine as well as improve the transfer of codified artifacts between parties. Thus, the following is proposed:

Hypothesis 2b. (H2b): UAI levels at the knowledge sender location are positively associated with the knowledge receiver's level of process compliance.

\subsubsection{Long-term Orientation}

LTO relates to the extent to which individuals are willing to make short-term sacrifices for longterm gains (Voss and Blackmon 1998). Strict adherence to high levels of process compliance is typically costly in the short term (Cosel 2011) and beneficial in the long term (Crosby 1979). Knowledge receivers with a LTO are thus more likely to tolerate short-term compliance costs, such as production downtime while investigating possible process non-compliance, because they accept that non-compliance may have more significant long-term ramifications, such as recalls, fines, or lost goodwill. This tendency leads to the following:

Hypothesis 3a. (H3a): LTO levels at the knowledge-receiver location are positively associated with the knowledge receiver's level of process compliance.

Knowledge senders high in LTO are more likely to carefully implement robust and possibly redundant process compliance systems at the knowledge-receiver location. Furthermore, the feedback to the knowledge receivers is more likely to emphasize that process compliance, in the long term, is in the best interests of the organization. Such feedback can come formally, such as through training and performance reviews, or informally, such as through employee conversations. Last, high LTO may relate to knowledge senders reacting less negatively in instances when the assurance of process compliance is costly in other performance dimensions, such as on-time delivery. Thus, the following is proposed: 
Hypothesis 3b. (H3b): LTO levels at the knowledge sender location are positively associated with the knowledge receiver's level of process compliance.

\subsubsection{Power Distance}

PDI measures the acceptance of unequal power distribution among members of the group. HighPDI cultures expect higher levels of the organizational hierarchy to dictate the operating procedures to lower levels. Lower-level employees in high-PDI cultures tend to accept these dictated orders and resist questioning the judgment of their superiors. In settings where the knowledge sender is an HQ, the knowledge sender tends to be viewed as higher in the organizational hierarchy than the knowledge receiver.

Hypotheses regarding PDI need to be bounded in the following way: In settings in which the ostensive components of necessary routines can be fully codified into unchanging artifacts and these artifacts can always be followed without sacrificing other performance dimensions, PDI may facilitate process compliance. This is because higher level employees can dedicate efforts to linking artifacts to ostensive components of the routine, and lower level employees will perform according to these artifacts without question. However, very few real-world settings possess these traits. In more typical settings, some portion of the ostensive routine is tacit and cannot be codified (Pentland and Feldman 2005). Thus,

some level of discretion and ambiguity at the performative level exists. Knowledge receivers that are high in PDI typically are less engaged in the creation of artifacts that match the ostensive components. Furthermore, as planned or unplanned modifications to the routine naturally arise over time (Anand et al. 2012), knowledge receivers high in PDI are less likely to raise their ongoing concerns, impeding correction, or recalibration of the artifacts. Thus, the following is proposed: 
Hypothesis 4a. (H4a): PDI levels at the knowledge receiver location are negatively associated with the knowledge receiver's level of process compliance.

Similarly, knowledge senders high in PDI are less prone to listen to the concerns of knowledge receivers. This may lead to a less rich discussion as artifacts are developed. Thus, the receiver may not understand the ostensive aspects of the routine and the sender may not understand the performative aspects of the routine. Furthermore, knowledge senders high in PDI may be less inclined to recalibrate existing artifacts at the request of knowledge receivers, even if compliance suffers. Thus, the following is proposed:

Hypothesis 4b. (H4b): PDI levels at the knowledge sender location are negatively associated with the knowledge receiver's level of process compliance.

\subsubsection{Individualism}

IDV measures the extent to which individuals are expected to focus on themselves or their immediate families rather than the collective whole (Hofstede 2001). In cultures high in IDV, workers prefer to work alone and are often motivated by individual reward structures. When compared with, for example, productivity, day-to-day process compliance can be less visible and therefore less subject to individual rewards (Anand et al. 2012). Holmstrom and Milgrom (1991) demonstrated that when faced with multiple objectives, individuals focus on the most observable ones. Taken together, knowledge receivers high in IDV are thus more likely to deviate from the artifact and/or ostensive components of a routine when compliance is difficult or other, more visible performance objectives exist. Thus, the following is proposed:

Hypothesis 5a. (H5a): IDV levels at the knowledge receiver location are negatively associated with the knowledge receiver's level of process compliance. 
A knowledge sender high in IDV is also more likely to optimize his or her own most salient performance objectives. The level of process compliance for distant locations-which employ many individuals and maintain separate management structures - may not be as salient a performance objective for knowledge senders as other competing objectives. Similarly, when a knowledge sender is high in IDV, the codifying of artifacts is likely to occur in isolation from the knowledge receiver's activities. Thus, a knowledge sender high in IDV may be more likely to create difficult-to-follow artifacts and also may expend less effort transferring the non-codifiable aspects of the ostensive routine. Thus, the following is proposed:

Hypothesis 5b. (H5b): IDV levels at the knowledge sender location are negatively associated with the knowledge receiver's level of process compliance.

\subsection{HQ-Plant National Culture Congruence and Plant-Level Process Compliance}

Beyond these direct effects of cultural attributes on process compliance, the discussion now addresses whether and how sender-receiver congruence in each of these cultural dimensions relates to process compliance. The arguments are tied closely to H1. With regard to cultural differences, Schein's (1985) theory argues that a set of basic assumptions and values exists at an unconscious level and serves as the foundation for the more visible artifacts of a culture. These underlying assumptions are indeed tacit elements of knowledge. Culture can also define what behaviors or norms are acceptable in the workplace (O'Reilly and Chatman 1996). Taken together, when the underlying cultural assumptions differ between knowledge sender and receiver, knowledge transfer can be inhibited (Bhagat et al. 2002). This, in turn, can inhibit the creation of artifacts consistent with the ostensive aspects. It can also inhibit the execution of performative aspects of the routine in accordance with artifacts and/or ostensive aspects of the routine. While the measure proposed by Kogut and Singh (1988) assesses aggregate cultural distance, here we assert that each of Hofstede's (2001) cultural dimensions can individually influence the unconscious behaviors of individuals. Thus: 
Hypotheses 6a-d. (H6a-d): Sender-receiver congruence in the [UAI(a), LTO(b), PDI(c), IDV(d)] cultural dimension is positively associated with the knowledge receiver's level of process compliance.

H6a-d focus entirely on congruence in cultural dimensions. Other interesting relationships between the two locations' cultural dimensions and process compliance, beyond congruence, are likely to exist. For example, if IDV inhibits knowledge transfer, as argued in H5, congruence at high levels of IDV may be worse for process compliance than, for example, low plant IDV and high HQ IDV. These types of relationships will be qualitatively examined in an exploratory fashion using three-dimensional surface plots generated from polynomial regression models.

\section{EMPIRICAL CONTEXT, DATA, AND OPERATIONALIZATION}

The context of this study is the drug manufacturing industry. This industry presents an ideal context in which to test the hypotheses for several reasons. First, lapses in quality can lead to illness or death, and the financial implications can easily be in the hundreds of millions of dollars (Harris and Wilson 2010). All company plants are thus expected to be strongly motivated to operate in compliance regardless of location. Second, significant within-industry variation exists with respect to plant and HQ location. Finally, the industry is governed and monitored by a third-party organization, the US Food and Drug Administration (FDA), which provides the dependent variable for this study.

\subsection{Dependent Variable: FDA Inspection Data}

The primary data used to test the hypotheses were obtained through a Freedom of Information Act request to the FDA. The FDA is a government agency tasked with ensuring the purity, safety, and efficacy of foods, drugs, cosmetics, and medical devices. It does this, in part, through facility inspections 
that are intended to detect a facility's adherence to GMPs. FDA inspections are typically conducted by a team of expert employees and involve analyses of plant records, interviews with facility employees, and tours of manufacturing facilities. On average, each inspection requires approximately 100 person hours of FDA inspector time. Our dataset contains the outcomes of all pharmaceutical manufacturing plant inspections conducted by the FDA between January 1994 and January 2007, a period during which the inspection protocol was reasonably consistent. For the analysis, each plant was required to have had least three inspections, resulting in a sample of 10,180 inspections, 1557 plants, and 953 firms. To satisfy model specifications (detailed in section 'Analysis'), the first observation for each plant in the database was dropped. Also dropped were plants for which any data were not populated, reducing the final sample to 8501 inspections, 1554 plants, and 941 firms. Summary statistics for this sample are provided, at the inspection level, in Table 2.

FDA inspections are conducted in accordance with federal regulations (21 CFR §210 and §211). These guidelines set forth GMPs that should be followed to reduce the likelihood of nonconforming outgoing product. Upon completion of the inspection, the FDA inspectors submit an Establishment Inspection Report (EIR) to the FDA's regional district. District personnel choose one of three possible district decisions for each inspection, listed in order of decreasing process compliance levels: No Action, Voluntary Action, and Official Action. Following the recent literature (Anand et al. 2012, Macher et al.

2011), these district decisions are treated as an ordinal, three-level measure of process compliance-the dependent variable for the analyses. Specifically, we code No Action = 2, Voluntary Action = 1, and Official Action $=0$.

\subsection{Independent Variables: Language Difference and Cultural Dimensions}

For H1, language difference was captured with a binary variable equal to 0 if the plant and HQ countries share the same primary language and equal to 1 otherwise, consistent with previous literature 
(Varonis and Gass 1985). In this study, primary languages for each country were obtained from the US Central Intelligence Agency's (CIA's) World Factbook (CIA 2012). In all, 22 unique primary languages are represented in the final dataset.

The national culture measures published in Hofstede (2011) were employed for use in H2 through H6. These scales were used to associate two cultural scores for each inspection—one for the manufacturing plant and one for the corporate HQ location. The Hofstede (2011) values were used as originally reported, with one exception. As in Gray et al. (2011), Puerto Rico was treated as a standalone country and assigned the Hofstede scores for Latin American countries (PDI = 70, UAI = 85, IDV = 21). Cultural values for PDI, UAI, and IDV were thus obtained for all 34 countries in our dataset. LTO was obtained for 28 of the 34 countries. Robustness checks with the GLOBE measures, which are also widely adopted (House et al. 2004), were performed and results are discussed in Section 4.3. All cultural dimensions were mean-centered prior to use in the regression models.

\subsection{Control Variables}

Various control variables were employed for the analysis. At the inspection level, the outcome of the plant's previous inspection, the natural log of the number of days since the previous inspection, and the interaction between these were included. Also included were sets of dummy variables for the type of inspection (surveillance, compliance, complaint) and whether an ownership change (merger, acquisition, spinoff) had occurred since the plant's last inspection. Dummy variables were also included for the year in which the inspection took place. Thus, the full set of inspection-level control variables considered in Anand et al. (2012) was also controlled for in this study. In addition, the HQ-plant geographic distance at the time of inspection was included. To populate this information, geographic coordinates for each inspection's HQ and plant location were added and then the GeoDist function in SAS 9.3 was applied to determine the distance in miles between the locations. The natural log of this distance was used due to the 
heavily right-skewed distribution of this variable. Also included was a series of dummy variables to control for industry. To control for differences in the execution of inspections between foreign and domestic plants (Cosel 2011), a dummy variable was included to capture whether the plant was under the FDA's US jurisdiction (which includes Puerto Rico).

\section{ANALYSIS}

The unit of analysis for this study is the individual FDA inspection. Here, inspections are nested within plants, and plants are nested within firms. Thus, it is necessary to consider the hierarchical nature of the error term in the regression model. We initially attempted to conduct the analyses with random effects included at both the firm and plant levels. However, the associated maximum likelihood estimates for these models generally failed to converge because plants were not fully nested within firms (plants often changed firm-level affiliations through ownership changes). Due to statistical challenges regarding fixed effects in ordered probit regression models (Greene 2004), fixed effects were not included. Thus, for

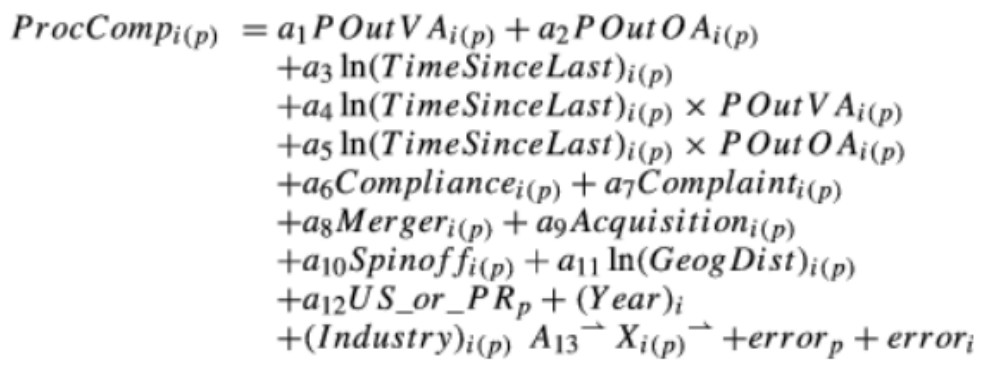

the primary analyses, random effects for the plant level were included. An alternative model specification that includes firm-level fixed effects is offered as a robustness test in section 'Robustness Tests and Supplemental Analyses'. The primary analysis was carried out using the GLLAMM procedure in STATA 12. The general model specification is as follows, where inline image in the model specification represents the vector of independent variables required for testing each of the individual hypotheses, for inspection i nested in plant p. 
H6a-d are tested using Edwards' (2002) methodology, whereby inline image takes the form:

\subsection{Hypothesis Test Results}

Results of the analyses are summarized in Table 3. The control variables are consistent with prior $b_{1}$ Plant_Value $+b_{2} H Q_{-}$Value $+b_{3}$ Plant_Value ${ }^{2}+b_{4}$ Plant $\times H Q_{-}$Value $+b_{5} H Q_{-}$Value ${ }^{2}$. literature, most notably the "decaying” of process compliance with time since the last inspection (Anand et al. 2012). Similar to Gray et al. (2011), a counterintuitive positive relationship exists between process compliance and the control variable geographic distance. Control variable estimates are generally stable across all models.

As shown in Model 1 of Table 3, the coefficient for language difference (LangDiff) is negative and highly significant ( $<$ 0.01), providing strong support for H1. In assessing H2 through H5 (Models 2-5), LangDiff is included as a control variable. For each of H2-H5, three models are analyzed. One includes just the plant-level cultural dimension, one includes just the HQ-level cultural dimension, and the third simultaneously includes both. For brevity, only the models with both plant and HQ dimensions are presented in Table 3. H2-H4 are not supported in any model ( $\mathrm{p}>0.05)$. H5, regarding IDV, is contradicted by the results. In models with just the plant or just the HQ location (not shown), Plant_IDV $(\mathrm{p}<0.05)$ and HQ_IDV $(\mathrm{p}<0.05)$ are significant, but in the opposite direction proposed by H5a-b. HQ_IDV retains its significance $(\mathrm{p}<0.05)$ in Model 5, which includes both locations simultaneously. These surprising results do not hold in most robustness tests, however.

The hypotheses regarding the effect of an HQ-plant cultural congruence (H6a-H6d) are assessed using polynomial regression (Edwards 2002). As language and cultural differences are conceptually intertwined (Schein 1985), LangDiff is omitted as a control variable in these polynomial models. An idealized congruence effect can be characterized using the following criteria (each bi refers to the respective term in the specification given in the final paragraph before section 'Hypothesis Test Results'): (1) the quantity (b3 - b4 + b5) should be negative, (2) the quantity (b1 + b2) should equal 0 , (3) the 
quantity (b3 + b4 + b5) should equal 0, (4) the first principal axis of the surface should have a slope of 1, and (5) the first principal axis of the surface should have an intercept of 0 (Edwards 2002). As suggested in Edwards (2002), a bootstrap program with 10,000 repetitions was created to estimate the standard errors for the slope and intercept of the first principal axis. Random effects were omitted in creating these bootstrap estimates as the exponential increase in computation time made including them computationally intractable.

The introduction of the polynomial regression terms significantly improved model fit over a controls-only model for UAI (Model 6) and PDI (Model 8). For PDI (Model 8), strong evidence suggests a congruence effect, supporting H6c, as all five conditions of Edwards (2002) were met. Thus, process compliance is indeed maximized when plant and HQ PDI are congruent. The surface plot for PDI, shown in Figure 1b, clearly illustrates this congruence relationship. Regarding UAI (Model 6), the primary condition for congruence (Condition (1) of Edwards 2002) is not met (i.e., failure to reject H0: b3 - b4 + $\mathrm{b} 5 \geqslant 0, \mathrm{p}=0.47$. Qualitatively, Figure $1 \mathrm{a}$ implies a negative relationship between plant UAI and process compliance, which is counter to H2a. The figure also shows little relationship between HQ UAI and process compliance. We now provide a possible post hoc explanation for these two relationships (and thank an anonymous reviewer for suggesting this explanation). Recall that H2a focused on how UAI affects comfort with ambiguity and uncertainty: high discomfort with these things leads to a natural tendency to comply with processes. However, Hofstede's (2013) definition also states: “Countries exhibiting strong UAI maintain rigid codes of belief and behavior and are intolerant of unorthodox behavior and ideas. Low UAI societies maintain a more relaxed attitude in which practice counts more than principles.” As previously articulated, process compliance involves executing performative routines consistent with the requirements from headquarters. At times, plants must change existing performative routines per the expectations of headquarters to maintain compliance. Based on the part of the UAI definition in this paragraph, individuals in low-UAI cultures may be more willing to make such changes than those in high-UAI cultures, explaining the negative relationship in plant-level UAI. Furthermore, 
since the HQ does not have to change its routines, its UAI has no relationship with a plant's process compliance.

The LTO polynomial model was marginally significant (Model 7; $<<0.10$ ); however, the primary congruence condition is not met for LTO (i.e., failure to reject $\mathrm{H0}$ : $\mathrm{b} 3-\mathrm{b} 4+\mathrm{b} 5 \geqslant 0, \mathrm{p}=0.62$ ). Therefore, H6b is not supported. This study does not report on the polynomial model for IDV, as the inclusion of the additional terms resulted in severe multicollinearity issues (for the five terms in the polynomial regression, inline image, well above a high-end cutoff of 10 [Hair et al. 1998, p. 221]). For the reference of future researchers, the surface plot generated by the model is qualitatively similar to that of UAI in that process compliance decreases with increases in plant IDV and there appears to be little relationship between HQ IDV and process compliance.

\subsection{Practical Significance}

Next, the practical significance of $\mathrm{H} 1$ is assessed by presenting the effect of a language difference on the probability of each inspection outcome. Here, the coefficient estimates provided in Model 1 were used. As described in section 'Dependent Variable: FDA Inspection Data', each inspection outcome represents a different level of process compliance. Specifically, No Action indicates a high level of process compliance, and Official Action indicates a low level of process compliance, with Voluntary Action falling between these outcomes. The first bar in Figure 2 represents the probability of each outcome for a hypothetical inspection in the year 2000 for a US pharmaceutical plant with the following characteristics: no ownership change since the plant's last inspection, no HQ-plant language difference, HQ-plant geographic distance $=3000$ miles, and a previous surveillance inspection that occurred 315 days ago with a Voluntary Action result. The second bar represents an identical scenario, except that there is an HQ-plant language difference. Here, the magnitude of the language difference has strong practical significance: The presence of a LangDiff results in a 37\% increase in the probability of the worst 
outcome, Official Action, signaling low compliance (from 10.9\% to 14.9\%). These Official Action outcomes are typically accompanied by a warning letter, which is made public (posted to the FDA's website), threatening injunction or seizure if deviations are not corrected, indicating the FDA's perception of their severity. This relationship qualitatively holds in other scenarios. Thus, one can conclude that a language difference between the HQ and the plant indeed relates to a practically significant decrease in process compliance.

\subsection{Robustness Tests and Supplemental Analyses}

The first assessments evaluate the sensitivity of the H1 result to specific geographic locations, as the original analysis had a heavy weighting of US-based plants. To do this, Model 1 was re-estimated for the following groups of plants: (1) within the 50 United States (75\% of plants), (2) within the 50 United States plus Puerto Rico (80\% of plants), (3) outside the 50 United States (25\% of plants), and (4) outside the 50 United States and outside Puerto Rico (20\% of plants). Due to the smaller sample size, some controls were dropped for groups (3) and (4). Support for H1 was robust in the larger subgroups, groups (1) and (2) (p < 0.01), but not in the much smaller groups, (3) and (4) ( $>>0.10)$. This result may be partially attributable to the fact that most of the non-US locations are in Europe, a region with many multilingual individuals who may be less affected by language differences than individuals in US plants.

The next analyses assessed the sensitivity of the results to the choice of measures of national culture. We replicated our original analyses, substituting the "values" measures from the GLOBE national culture study (House et al. 2004) for the Hofstede (2011) measures. The results indicated consistent support for $\mathrm{H} 1$ throughout all models ( $\mathrm{p}<0.01$ in all instances). The direct effects of national culture are also similar, with no significance found in Models 2 through $5(\mathrm{p}>0.10)$. The GLOBE polynomial regression models were also significant in the case of UAI and PDI. For PDI, the GLOBE model also found evidence of congruence, consistent with the Hofstede model. Regarding the UAI polynomial 
model, the GLOBE analyses did indicate a congruence relationship (i.e., Congruence Criterion 1 is met; p $<0.01$ ), providing support for H6a, whereas with the Hofstede measures this was not the case. The LTO dimensions were also not significant in the GLOBE polynomial model, again providing no support for H6b. In the case of IDV, two separate sets of analyses were conducted-one for each related GLOBE value (Institutional and Group Collectivism, which were reverse coded and named Institutional and Group IDV). Polynomial models employing the GLOBE IDV measures demonstrated even more severe issues with multi-collinearity than those in the main analysis. As such, results are not reported.

The main analyses did not include LangDiff when testing H6a-d due to a known relationship between language and culture (Schein 1985). Indeed, the mean correlation between LangDiff and the absolute difference between the HQ and plant cultural dimensions is 0.80. When LangDiff is included, none of the polynomial regression models significantly improved fit over and above Model 1. LangDiff remained negative and significant in these models.

Next, a supplemental analysis employing Kogut and Singh's (1988) widely utilized “cultural distance” measure was conducted. We chose not to employ this measure in the main analysis due to its established shortcomings (Kirkman et al. 2006, Shenkar 2001), but included this analysis to relate directly to the large amount of literature that has employed this measure. When the Kogut-Singh measure was simply substituted for LangDiff in Model 1, the Kogut-Singh measure had a negative and strongly significant $(\mathrm{p}<0.01)$ relationship with process compliance. When the measure was added to Model 1 (both LangDiff and the Kogut-Singh measure were included), LangDiff remained negative and nearly significant $(p=0.052)$, whereas the Kogut-Singh measure dropped to non-significance $(p=0.29)$. Considered along with the previous paragraph, it seems that a language difference dominates a cultural difference as they relate to process compliance performance.

No firm-level practices (such as training programs, technological implementations, and performance evaluations) were observed and, in the main analysis, firm-level effects were not included to maintain computational tractability. To assess the sensitivity of the findings to these omissions, we 
analyzed an alternative specification with the plant as the unit of analysis and including firm-level fixed effects. A fixed-effects analysis controls for firm-level practices to the extent that they are homogenous within firms. Any plants that underwent an ownership change during the study period were excluded. Here, each plant's mean inspection outcome was used and treated as a continuous dependent variable, allowing for the estimation of firm fixed effects. H1 was again robust to this alternative specification (p < 0.05), indicating that this result is not adversely affected by unobserved firm-level heterogeneity. After controlling for LangDiff, no significant relationship was apparent between any of the plant-level cultural dimensions and compliance ( $\mathrm{p}>0.05)$. Note that HQ cultural dimensions and polynomial models were not tested, as the inclusion of HQ-level fixed effects controlled for these dimensions.

Finally, a difference-in-difference analysis was performed to partially address concerns regarding omitted variables bias (Wooldridge 2010). Considering only plants with a pre-ownership-change LangDiff $=1$, we compared those plants undergoing both an ownership change and a change in LangDiff to plants undergoing only an ownership change. To do this, we analyzed the difference-in-difference for the inspection immediately preceding the ownership change and the inspection immediately following it across the two groups, while controlling for the key significant factors in Model 0. Plants with LangDiff = 1 after the ownership-changing activity (i.e., no change in LangDiff) were deemed the control group, and those with LangDiff $=0$ after the change composed the treatment group. This analysis provided some support for H1: The difference-in-difference estimator is positive and moderately significant $(\mathrm{p}=0.06)$, indicating that the removal of an HQ-plant language difference effectively improves process compliance. A comparable test among plants that had no language difference before the ownership change was directionally as expected but not significant $(\mathrm{p}=0.21)$.

In sum, the robustness tests indicate that the initial findings for $\mathrm{H} 1-\mathrm{H} 6$ are generally robust. The only exceptions to this statement are (1) the direct effects of IDV tended to fall to non-significance and (2) the GLOBE analyses indicated that plant-HQ congruence along the UAI dimension relates to higher compliance levels. Most consistent in the analyses were that (1) a plant-HQ language difference relate to 
lower compliance levels and (2) plant-HQ congruence along the PDI dimension relates to higher compliance levels.

\section{DISCUSSION AND CONCLUSION}

We first discuss our results in light of the international operations management (OM) literature, which has typically neglected language and national culture (Metters 2008) and contingencies in general (Sousa and Voss 2008). Recent studies on service offshoring have considered these factors conceptually (Metters et al. 2010, Stringfellow et al. 2008) and as predictors of location choice (Hahn and Bunyaratavej 2010). Survey-based studies related to quality in manufacturing have reported inconsistent relationships between national culture and practice implementation (Flynn and Saladin 2006, McKone et al. 1999, Power et al. 2010, Voss and Blackmon 1998). Regarding national culture and performance, similar to Naor et al. (2010) and Kull and Wacker (2010), this research did not find consistent evidence that individual national cultural dimensions directly affect operational performance. Kull and Wacker (2010) did report that UAI related to improving the effectiveness of quality management (QM) programs on product quality performance, similar to H2a but counter to the conclusion one would draw qualitatively from examination of Figure 1a. When considered along with such previous literature, the results of this study indicate that the direct effect of national culture on operational performance is not yet well-understood.

Beyond previous studies, this study provides new evidence that congruence between the plant and HQ in the national cultural dimension of PDI is consistently related to improved process compliance performance. Some evidence-in the GLOBE measures only—suggests that congruence along the UAI dimension is also related to improved process compliance performance. We found no evidence of a congruence effect for the LTO cultural dimension, and could not effectively analyze congruence in the IDV dimension due to multi-collinearity. It is important to note that the congruence test may be 
confounded by other factors, possibly explaining non-significant findings. For example, in some cases, congruence may be dominated by direct effects of specific cultural dimensions at just one location. Collectively, the findings indicate that the effects of cultural congruence depend on the specific cultural dimension being investigated, further indicating that an aggregate "cultural distance” measure should not be employed. Most importantly, the study provides a new contingency factor in international OM research, plant-HQ language difference. These results contribute to the ongoing debate regarding the universality of operational practices (Rungtusanatham et al. 2005). The above discussion implies that operational performance can be achieved in any national culture, but that two key HQ-plant differences, language and PDI, relate to decreased process compliance performance. The results of this study are interesting in light of Handley and Benton's (2013) study, which found, counter to expectations, that cultural distance related to decreased control and coordination costs in offshore outsourcing (language difference was not studied). Combined with our findings, these results could indicate that firms treat offshore operations (with different cultures and languages) according to the philosophy of "out of sight, out of mind.” If true, this provides another driver of our language difference and congruence results. Beyond OM, this research contributes to other literature bases, including the international business literature related to national culture (Kirkman et al. 2006, Tung and Verbeke 2010) and language (Harzing and Feely 2008, Luo and Shenkar 2006), as well as the knowledge management literature (Van Wijk et al. 2008).

For managers, this study articulates the mechanisms by which process compliance performance can be hindered by language and cultural differences. Our study suggests that such performance is significantly hindered by differences in language and PDI in a large and prominent global industry. These results suggest that additional costs to mitigate this tendency and costs to remedy the increased lack of compliance should be included in any total cost analysis when considering production locations with differences in these dimensions. Practitioners often overlook this and other hidden aspects when making location decisions (Accenture 2011). This study found inconsistent direct effects of individual cultural 
attributes on process compliance performance. These findings (combined with those of previous literature) imply that differences in national culture between HQ and the plant affect performance more than the absolute level of any specific cultural dimension.

This study is not without limitations. First, the three-level dependent variable is a coarse and imperfect measure of plant-level process compliance. The lack of significance in some of the hypothesis tests may be partially attributable to this. Second, the longitudinal and secondary data do not facilitate investigation into the organizational culture of the plants and/or HQs in the sample (Naor et al. 2010). Furthermore, the data do not offer visibility into the approaches used by firms to ensure process compliance. Approaches may include, for example, certain training practices, job rotation, and techniques for evaluating performance. To the extent that these are correlated with but not caused by (Schleifler 1994) the presence of a language difference, omitting these from the regression may have affected the results. In addition, the IDV polynomial model could not be fully analyzed due to multi-collinearity issues in the data. Finally, numerous plants in the sample are from one country (the United States), reducing variance in the national culture variables, possibly explaining some of the non-results in these analyses.

The results, particularly the consistently supported language difference effect, are powerful for three reasons. First, the dependent variable has a small tacit component, especially when compared to other performance dimensions such as research and development productivity. These findings are likely to be more pronounced in those settings (Szulanski 2000). Second, the wholly owned operations in the research setting do not require knowledge to traverse organizational boundaries. Presumably, the differing firm-level organizational cultures and differing incentives in an inter-firm setting would amplify the challenges (Handley and Gray 2013). Third, nearly all of the plants studied reside in developed economies not typically associated with process compliance challenges. Taken together, the findings could imply that the incidents in which Chinese-made products of Western firms have been recalled may have resulted from the language difference and the large difference in PDI (China $=80$, United States $=$ 40) between the Chinese manufacturing plants and the Western HQs. This would provide a different 
explanation than attributing the spate of recalls to characteristics of Chinese suppliers (Midler 2009, Roth et al. 2008). 


\section{Acknowledgments}

The authors would like to acknowledge the Center for International Business Education and Research at the Fisher College of Business at the Ohio State University for providing funding to enable part of the data collection effort for this paper. We would also like to thank Eric Nash and Megan Mickley for performing multiple data collection and cleansing tasks. 
FIGURE 1. The Effect of Language Differences and National Culture on Operational Process

Compliance.
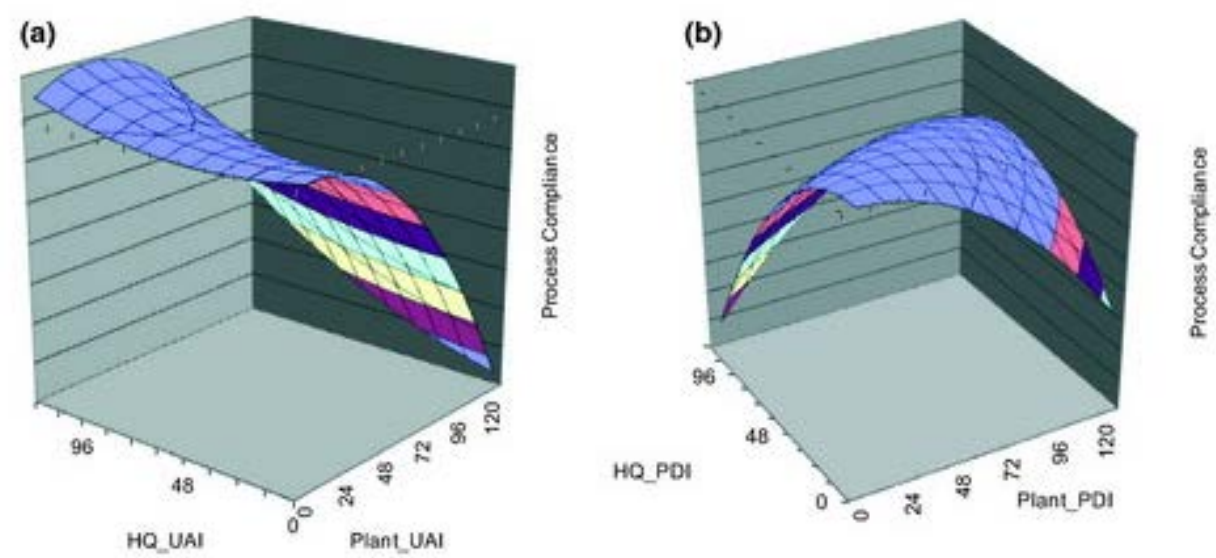
FIGURE 2. The Effect of Language Differences and National Culture on Operational Process Compliance.

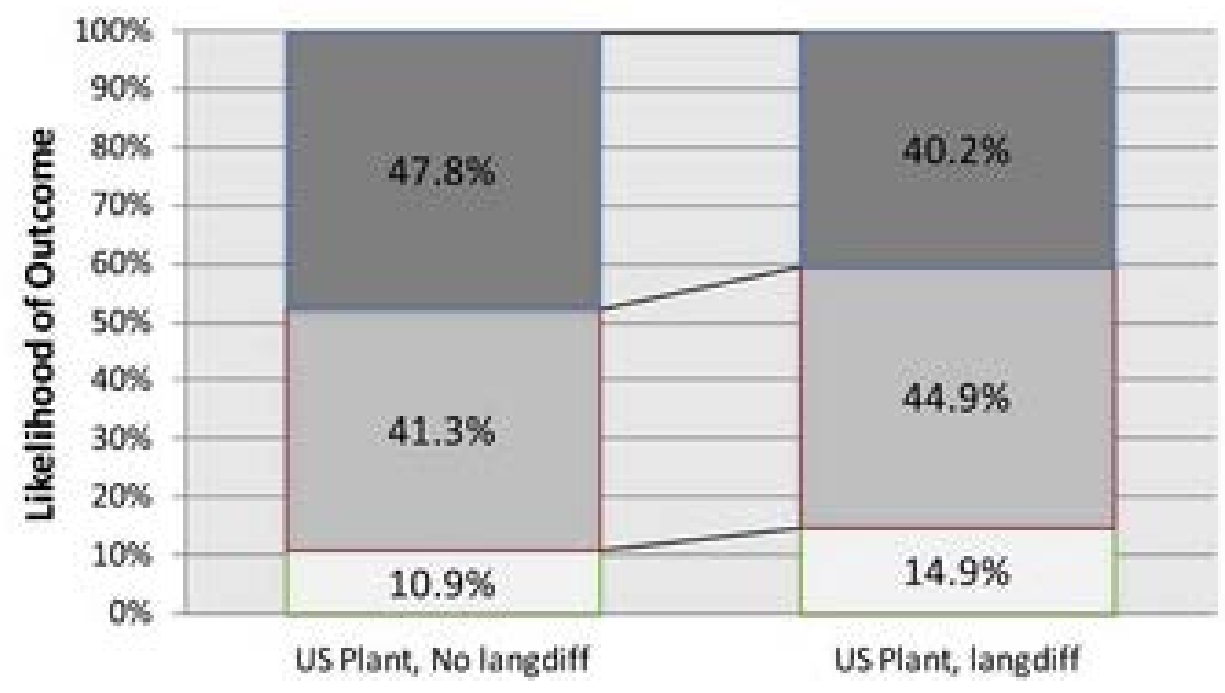

- High Compliance $\quad$ Medium Compliance $\square$ Low Compliance 
Table 1. Components of Organizational Routines

Component

name

Definition (quoted from Pentland and Feldman 2005)

“Abstract patterns that participants use to guide, account

Ostensive for, and refer to specific performances of a routine” (p. 795)

"Specific actions taken by specific people at specific

Performative times when they are engaged in what they consider an organizational routine” (p. 796)

"Physical manifestations of the organizational routine"

Artifacts (p. 797)
Examples (in the pharmaceutical manufacturing setting studied here)

Idealized conceptualizations of a routine. Examples:

1. Having the right amount of the right material in each product

2. Ensuring that the process operates as designed

3. Having the equipment maintained in such a way that it will operate consistently as it did at startup

4. Ensuring no cross-contamination between different products

Actual performances of regular tasks or work processes, such as:

1. Adding a raw material to a batch of product (with two people witnessing each addition)

2. Recording process characteristics (e.g., temperature)

3. Performing a maintenance task (e.g., oiling a machine)

4. Changing over equipment between different products

Things the operators actually refer to and use (canonical example is stasndard operating procedures). Referring to examples above:

1. A procedure which outlines the amount of product and the exact procedure to add it; also, a log that requires two signatures for each addition

2. Visual control which indicates whether the process is within or not within targets for a specific characteristic

3. A system that reminds an operator that it is time to perform a specific maintenance procedure

4. Documentation of employee training on the changeover procedure 
Table 2. Descriptive Statistics (at the Inspection Level)

\section{Variable Observation Mean SD}

ProcComp (dependent variable) $8501 \quad 1.24 \quad 0.73$

$\begin{array}{lll}\text { Year } & 8501 & 2000.573 .59\end{array}$

Inspection history control variables

$\begin{array}{llll}\ln \text { (TimeSinceLast) } & 8501 & 5.71 & 1.24\end{array}$

Inspection-type control variables

Surveillance

$\begin{array}{lll}8501 & 0.68 & 0.47\end{array}$

Compliance

$\begin{array}{lll}8501 & 0.31 \quad 0.46\end{array}$

Complaint

$\begin{array}{lll}8501 & 0.02 & 0.12\end{array}$

Ownership-changing indicators

Merger

Acquisition

Spinoff

HQ-plant distance variables

$\begin{array}{lrrr}\text { LangDiff } & 8501 & 0.21 & 0.41 \\ \text { ln(HQ-plant Geog Dist) } & 8501 & 4.81 & 3.05 \\ \text { US_or_PR } & 8501 & 0.88 & 0.33 \\ \text { Hofstede (2011) cultural dimensions } & & \\ \text { Plant_UAI } & 8501 & 50.65 & 13.11 \\ \text { HQ_UAI } & 8501 & 50.38 & 12.33 \\ \text { Plant_PDI } & 8501 & 42.93 & 9.93 \\ \text { HQ_PDI } & 8501 & 40.67 & 8.75 \\ \text { Plant_LTO } & 7847 & 30.57 & 8.37 \\ \text { HQ_LTO } & 8236 & 31.78 & 10.11 \\ \text { Plant_IDV } & 8501 & 82.77 & 20.09 \\ \text { HQ_IDV } & 8501 & 84.34 & 14.10\end{array}$




\section{Table 3. Results from Ordered Probit Regression, H1-H6 (DV=ProcComp)}

Model 0 Model $1 \quad$ Model $2 \quad$ Model $3 \quad$ Model $4 \quad$ Model 5

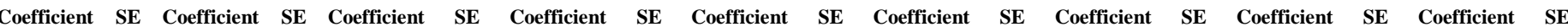

1. ${ }^{*} p<0.10,{ }^{* *} p<0.05,{ }^{* * *} p<0.01$. Note: LR test statistics are based on a comparison to a null model including only control variables. For Models 2 through 5 , LangDiff is treated as a control variable

2. For Models 3 and 7 (LTO), the Log Likelihood tests are conducted using a form of Model 0 which excludes observations missing LTO data $(n=7696$; not shown).

Inspection-level controls

Previous outcome

\begin{tabular}{|c|c|c|c|c|c|c|c|c|c|c|c|c|c|c|c|c|}
\hline POutVA & -0.07 & $(0.14)-0.06$ & $(0.14)-0.06$ & $(0.14)$ & -0.04 & $(0.14)$ & -0.06 & $(0.14)$ & -0.06 & $(0.14)$ & -0.06 & $(0.14)$ & -0.05 & $(0.14)$ & -0.07 & $(0.14)$ \\
\hline POutOA & $-0.78^{* * *}$ & $(0.18)-0.78^{* * *}$ & $(0.18)-0.78 * * *$ & $(0.18)$ & $-0.85^{* * *}$ & $(0.18)$ & $-0.78^{* * *}$ & $(0.18)$ & $-0.78 * * *$ & $(0.18)$ & $-0.78^{* * *}$ & $(0.18)$ & $-0.85^{* * *}$ & $(0.18)$ & $-0.78^{* * *}$ & $(0.18)$ \\
\hline $\ln$ (TimeSinceLast) & $-0.04 * *$ & $(0.02)-0.04 * *$ & $(0.02)-0.04 * *$ & $(0.02)$ & $-0.04 * *$ & $(0.02)$ & $-0.04 * *$ & $(0.02)$ & $-0.04 * *$ & $(0.02)$ & $-0.04 * *$ & $(0.02)$ & $-0.04 * *$ & $(0.02)$ & $-0.04 * *$ & $(0.02)$ \\
\hline $\ln ($ TimeSinceLast $) \times$ POutVA & -0.03 & $(0.02)-0.03$ & $(0.02)-0.03$ & $(0.02)$ & -0.03 & $(0.02)$ & -0.03 & $(0.02)$ & -0.03 & $(0.02)$ & -0.03 & $(0.02)$ & -0.03 & $(0.02)$ & -0.03 & $(0.02)$ \\
\hline $\ln ($ TimeSinceLast $) \times$ POutOA & $0.06 * *$ & $(0.03) 0.06 * *$ & $(0.03) 0.06 * *$ & $(0.03)$ & $0.07 * *$ & $(0.03)$ & $0.06 * *$ & $(0.03)$ & $0.06 * *$ & $(0.03)$ & $0.06 * *$ & $(0.03)$ & $0.07 * *$ & $(0.03)$ & $0.06 * *$ & $(0.03)$ \\
\hline \multicolumn{17}{|l|}{ Type (Surveillance omit) } \\
\hline Compliance & $-0.34 * * *$ & $(0.03)-0.33 * * *$ & $(0.03)-0.33 * * *$ & $(0.03)$ & $-0.32 * * *$ & $(0.03)$ & $-0.33 * * *$ & $(0.03)$ & $-0.33 * * *$ & $(0.03)$ & $-0.33 * * *$ & $(0.03)$ & $-0.32 * * *$ & $(0.03)$ & $-0.33^{* * *}$ & $(0.03)$ \\
\hline Complaint & $0.22 * *$ & $(0.11) \quad 0.22 * *$ & (0.11) $0.22 * *$ & $(0.11)$ & 0.20 & $(0.11)$ & $0.22 * *$ & $(0.11)$ & $0.22 * *$ & $(0.11)$ & $0.22 * *$ & $(0.11)$ & $0.20 *$ & $(0.11)$ & $0.22 * *$ & $(0.11)$ \\
\hline \multicolumn{17}{|l|}{ Ownership changing } \\
\hline Merger & -0.21 & $(0.12)-0.20$ & $(0.12)-0.21$ & $(0.12)$ & -0.20 & $(0.12)$ & -0.20 & $(0.12)$ & -0.22 & $(0.12)$ & -0.21 & $(0.12)$ & -0.20 & $(0.12)$ & -0.20 & $(0.12)$ \\
\hline Acquisition & 0.09 & (0.09) 0.09 & (0.09) 0.09 & $(0.09)$ & 0.08 & $(0.10)$ & 0.09 & $(0.09)$ & 0.09 & $(0.09)$ & 0.08 & $(0.09)$ & 0.08 & $(0.10)$ & 0.08 & $(0.09)$ \\
\hline $\ln$ (GeogDist) & $0.02 * * *$ & (0.01) $0.04^{* * *}$ & (0.01) $0.04 * * *$ & $(0.01)$ & $0.04 * * *$ & $(0.01)$ & $0.04 * * *$ & $(0.01)$ & $0.04 * * *$ & $(0.01)$ & $0.03^{* * *}$ & $(0.01)$ & $0.03^{* * *}$ & $(0.01)$ & $0.03 * * *$ & $(0.01)$ \\
\hline US_or_PR & 0.03 & (0.05) 0.03 & $(0.05)-2.9 \mathrm{e}-3$ & $(0.05)$ & 0.01 & $(0.05)$ & 0.02 & $(0.05)$ & -0.04 & $(0.05)$ & -0.03 & $(0.05)$ & 0.04 & $(0.05)$ & 0.01 & $(0.05)$ \\
\hline Year dummies & \multicolumn{2}{|l|}{ Not reported } & \multicolumn{2}{|c|}{ Not reported } & \multicolumn{2}{|c|}{ Not reported } & \multicolumn{2}{|l|}{ Not reported } & \multicolumn{2}{|l|}{ Not reported } & \multicolumn{2}{|l|}{ Not reported } & \multicolumn{2}{|c|}{ Not reported } & \multicolumn{2}{|c|}{ Not reported } \\
\hline Industry dummies & Not reported & Not reported & \multicolumn{2}{|c|}{ Not reported } & \multicolumn{2}{|c|}{ Not reported } & \multicolumn{2}{|l|}{ Not reported } & \multicolumn{2}{|c|}{ Not reported } & \multicolumn{2}{|l|}{ Not reported } & \multicolumn{2}{|c|}{ Not reported } & \multicolumn{2}{|c|}{ Not reported } \\
\hline
\end{tabular}




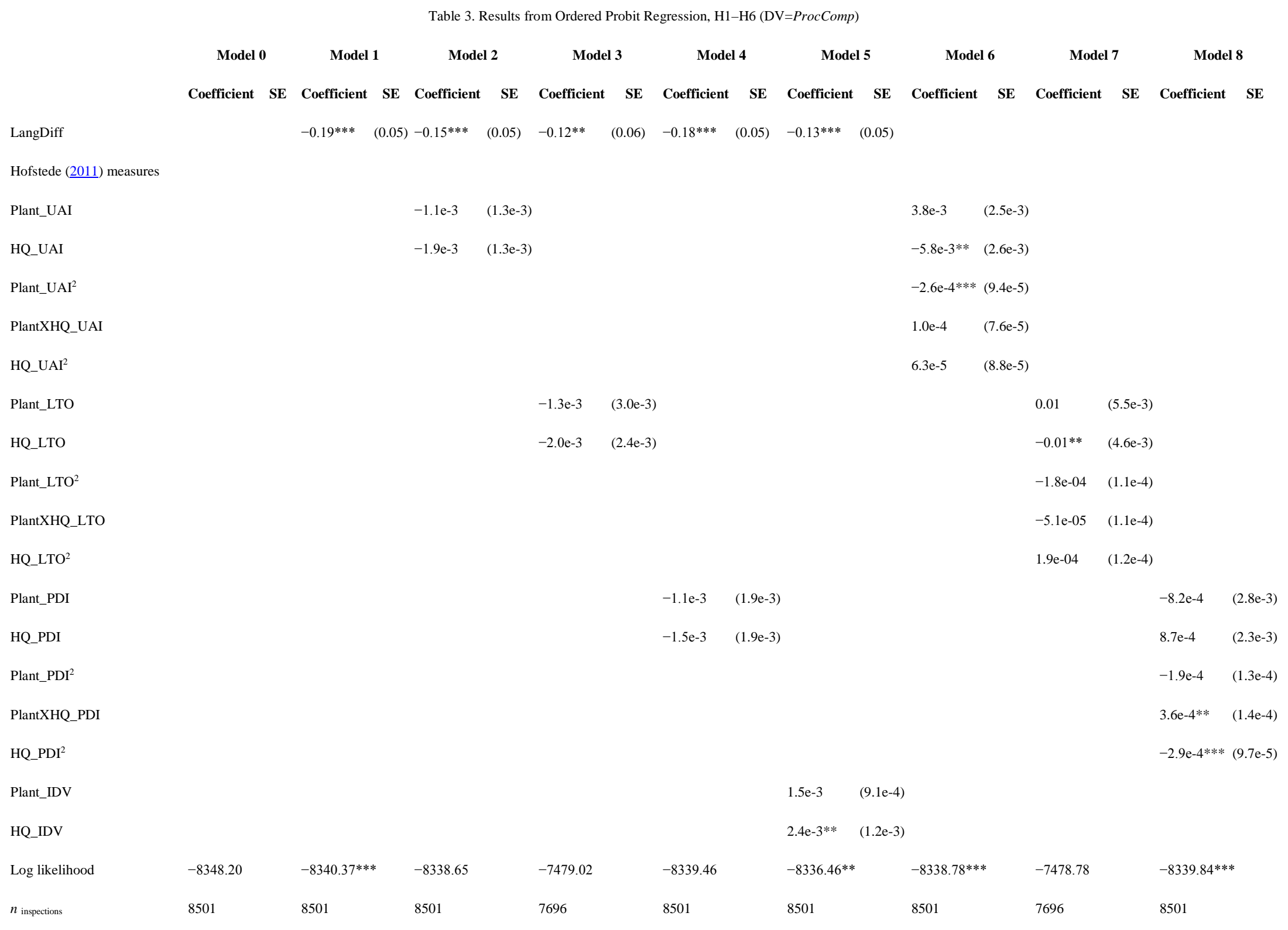


Table 3. Results from Ordered Probit Regression, H1-H6 (DV=ProcComp)

$\begin{array}{llllll}\text { Model } 0 & \text { Model } 1 & \text { Model 2 } & \text { Model } 3 & \text { Model } 4 & \text { Model } 5\end{array}$

Coefficient SE Coefficient SE Coefficient SE Coefficient SE Coefficient SE Coefficient
1554

1554
1456
1554
Model 6

Model 7

Model 8

Coefficient SE Coefficient SE Coefficient SE Coefficient $\quad$ SE 1554
1554

1456 


\section{REFERENCES}

Accenture. 2011. Manufacturing’s Secret Shift. Available at: http://www.accenture.com/SiteCollectionDocuments/PDF/Accenture_Manufacturings_Secret_Sh ift.pdf (accessed date July 1, 2013).

Anand, G., J. V. Gray, E. Siemsen. 2012. Decay, shock, and renewal: Operational routines and process entropy in the pharmaceutical industry. Org. Sci. 23(6): 1700-1716.

Bassnett, S. 2002. Translation Studies, 3rd ed. Routledge, New York, NY.

Bendoly, E., E. D. Rosenzweig, J. K. Stratman. 2007. Performance metric portfolios: A framework and empirical analysis. Prod. Oper. Manag. 16(2): 257-276.

Bhagat, R., B. Kedia, P. Harveston, H. Triandis. 2002. Cultural variations in the cross-border transfer of organizational knowledge: An integrative framework. Acad. Manage. Rev. 27(2): 204-221.

Chung, W., J. Alc_acer. 2002. Knowledge seeking and location choice of foreign direct investment in the United States. Manage.Sci. 48(12): 1534-1554.

CIA. 2012. The World Factbook. Available at https://www.cia.gov/library/publications/the-worldfactbook/ (accessed date January 31, 2013).

Cosel, G. 2011. After Heparin: Protecting Consumers from the Risks of Substandard and Counterfeit Drugs. Pew Health Group, Philadelphia, PA.

Crosby, P. 1979. Quality Is Free: The Art of Making Quality Certain. McGraw-Hill, New York, NY.

Crystal, D. 2003. English as a Global Language, 2nd edn. Cambridge University Press, Cambridge, UK. 
Davidson, W. H. 1980. The location of foreign direct investment activity: Country characteristics and experience effects. J. Int. Bus. Stud. 11(2): 9-22.

Edwards, J. 2002. Alternatives to difference scores: Polynomial regression analysis and response surface methodology. F. Drasgow, N. Schmitt, eds. Advances in Measurement and Data Analysis. Jossey-Boss, San Francisco, CA.

Ellram, L., W. Tate, C. Billington. 2008. Offshore outsourcing of professional services: A transaction cost economics perspective. J. Oper. Manag. 26(2): 148-163.

Ettredge, M., K. Johnstone, M. Stone, Q. Wang. 2011. The effects of firm size, corporate governance quality, and bad news on disclosure compliance. Rev. Account. Stud. 16(4): 866-889.

Feldman, M., B. Pentland. 2003. Reconceptualizing organizational routines as a source of flexibility and change. Adm. Sci. Q. 48(1): 94-118.

Ferdows, K. 1997. Made in the world: The global spread of production. Prod. Oper. Manag. 6(2): 102109.

Ferdows, K. 2006. Transfer of changing production know-how. Prod. Oper. Manag. 15(1): 1-9.

Ferdows, K., A. DeMeyer. 1990. Lasting improvements in manufacturing performance. In search of a new theory. J. Oper. Manag. 9(2): 168-184.

Fixman, C. 1990. The foreign language needs of U.S.-based corporations. Ann. AAPSS 511: 25-46.

Flynn, B. B., B. Saladin. 2006. Relevance of Baldrige constructs in an international context: A study of National Culture. J. Oper. Manag. 24(5): 583-603.

Giannetti, M., Y. Yafeh. 2011. Do cultural differences between contracting parties matter? Evidence from syndicated bank loans. Manage. Sci. 58(2): 365-383. 
Gray, J. V., A. V. Roth, M. J. Leiblein. 2011. Quality risk in offshore manufacturing: Evidence from the pharmaceutical industry. J. Oper. Manag. 29(7-8): 737-752.

Greene, W. 2004. The behaviour of the maximum likelihood estimator of limited dependent variable models in the presence of fixed effects. Econometrics J. 7: 98-119.

Hahn, E. D., K. Bunyaratavej. 2010. Services cultural alignment in offshoring: The impact of cultural dimensions on offshoring location choices. J. Oper. Manag. 28: 186-193.

Hair, J. F., R. E. Anderson, R. L. Tatham, W. C. Black. 1998. Multivariate Data Analysis. Prentice-Hall, Upper Saddle River, NJ.

Handley, S. M., W. C. Benton. 2013. The influence of task- and location-specific complexity on the control and coordination costs in global outsourcing relationships. J. Oper. Manag. 31: 109-128.

Handley, S. M., J. V. Gray. 2013. Inter-organizational quality management: The use of contractual incentives and monitoring mechanisms. Prod. Oper. Manag. 22(6): 1540-1556.

Harris, G., D. Wilson. 2010. Glaxo to Pay \$750 Million for Sale of Bad Products. Available at http://www.nytimes.com/2010/10/27/business/27drug.html?_r=1\&pagewanted=all (accessed date July 1, 2013).

Harzing, A., A. J. Feely. 2008. The language barrier and its implications for HQ-subsidiary relationships. Cross Cult. Manage. 15(1): 49-61.

Hayes, R. H., S. C. Wheelwright. 1984. Restoring Our Competitive Edge: Competing through Manufacturing. John Wiley \& Sons, New York, NY.

Hennart, J., 2009. Theories of the multinational enterprise, A. Rugman, ed. The Oxford Handbook of International Business. Oxford University Press, Oxford, 125-145. 
Hofstede, G. H. 2001. Culture’s Consequences: Comparing Values, Behaviors, Institutions, and Organizations across Nations. Sage Publications, Thousand Oaks, CA.

Hofstede, G. 2011. National Culture Dimension The Hofstede Centre. Available at http://geerthofstede.com/countries.html (accessed date January 1, 2012).

Hofstede, G. 2013. Dimensions - Geert Hofstede. The Hofstede Centre, Available at http://geerthofstede.com/dimensions. html (accessed date October 21, 2013).

Holmstrom, B., P. Milgrom. 1991. Multitask principal-agent analyses: Incentive contracts, asset ownership, and job design. J. Law Econ. Org. 7(Special Issue): 24-52.

House, R. J., P. J. Hanges, M. Javidan, P. W. Dorfman, V. Gupta. 2004. Global Leadership and Organizational Behavior Effectiveness Research Program. Culture, Leadership, and Organizations: The GLOBE Study of 62 Societies. Sage Publications, Thousand Oaks, CA.

Janssens, M., J. Lambert, C. Steyaert. 2004. Developing language strategies for international companies: The contribution of translation studies. J. World Bus. 39(4): 414-430.

Joseph, J. 1995. Indeterminacy, Translation, and the Law. John Benjamins Publishing Company, Amsterdam, The Netherlands.

Kirkman, B., K. Lowe, C. Gibson. 2006. A quarter century of culture’s consequences: A review of empirical research incorporating Hofstede’s cultural values framework. J. Int. Bus. Stud. 37(3): 285-320.

Klassen, R., D. C. Whybark. 1994. Barriers to the management of international operations. J. Oper. Manag. 11(4): 385-396. 
Kogut, B., H. Singh. 1988. The effect of national culture on the choice of entry mode. J. Int. Bus. Stud. 19(3): 411-432.

Kull, T. J., J. G. Wacker. 2010. Quality management effectiveness in Asia: The influence of culture. J. Oper. Manag. 28(3): 223-239.

Luo, Y., O. Shenkar. 2006. The multinational corporations as a multilingual community: Language and organization in a global context. J. Int. Bus. Stud. 37(3): 321-339.

Macher, J. T., J. W. Mayo, J. A. Nickerson. 2011. Regulator heterogeneity and endogenous efforts to close the information asymmetry gap. J. Law Econ. 54(1): 25-54.

Marschan-Piekkari, R., D. Welch, L. Welch. 1999. In the shadow: The impact of language on structure, power and communication in the multinational. Intl. Bus. Rev. 8(4):421-440.

McKone, K. E., R. G. Schroeder, K. O. Cua. 1999. Total productive maintenance: A contextual view. J. Oper. Manag. 17(2): 123-144.

Melnyk, S. A., D. M. Stewart, M. Swink. 2004. Metrics and performance measurement in operations management: Dealing with the metrics maze. J. Oper. Manag. 22(3): 209-218.

Metters, R. 2008. A typology of offshoring and outsourcing in electronically transmitted services. J. Oper. Manag. 26(2): 198-211.

Metters, R., X. Zhao, E. Bendoly, B. Jiang, S. Young. 2010. The way that can be told of is not an unvarying way: Cultural impacts on operations management in Asia. J. Oper. Manag. 28(3): 177185.

Midler, P. 2009. Poorly Made in China. John Wiley \& Sons Inc, Hoboken, NJ. 
Naor, M., K. Linderman, R. Schroeder. 2010. The globalization of operations in Eastern and Western countries: Unpacking the relationship between national and organizational culture and its impact on manufacturing performance. J. Oper. Manag. 28(3): 194-205.

Neeley, T. B. 2013. Status loss and achieved status distinctions in global organizations. Org. Sci. 24(2): 476-497.

Nelson, R., S. Winter. 1982. An Evolutionary Theory of Economic Change. Harvard University Press, Cambridge, MA.

Nida, E., C. Tabr. 2003. The Theory and Practice of Translation. Koninklijke Brill NV, Leiden, Netherlands.

Noorderhaven, N., A. Harzing. 2009. Knowledge-sharing and social interaction within MNEs. J. Int. Bus. Stud. 40(5): 719-741.

O’Reilly, C. A., J. A. Chatman. 1996. Culture as social control: Corporations, cults, and commitment. Res. Org. Behav. 18: 157-200.

Pentland, B., M. Feldman. 2005. Organizational routines as a unit of analysis. Ind. Corp. Change. 14(5): 793-815.

Polanyi, M. 1966. The Tacit Dimension. Doubleday, New York, NY. Power, D., T. Schoenherr, D. Samson. 2010. The cultural characteristic of individualism/collectivism: A comparative study of implications for investment in operations between emerging Asian and industrialized Western countries. J. Oper. Manag. 28(3): 206-222.

Pronovost, P., E. Vohr. 2010. Safe Patients, Smart Hospitals: How One Doctor’s Checklist Can Help Us Change Health Care from the Inside Out. Hudson Street Press, New York, NY. 
Puhakainen, P., M. Siponen. 2010. Improving employees’ compliance through information systems security training: An action research study. MIS Q. 34(4): 757-778.

Reagans, R., B. McEvily. 2003. Network structure and knowledge transfer: The effects of cohesion and range. Adm. Sci. Q. 48(2): 240-267.

Rosenzweig, E., A. Roth. 2004. Towards a theory of competitive progression: Evidence from high-tech manufacturing. Prod. Oper. Manag. 13(4): 354-368.

Roth, A. V., A. A. Tsay, M. E. Pullman, J. V. Gray. 2008. Unraveling the food supply chain: Strategic insights from China and the 2007 recalls. J. Supply Chain Manage. 44(1): 22-39.

Rugman, A. M., A. Verbeke. 2001. Location, Competitiveness, and the Multinational Enterprise. Oxford Handbook of International Business, Oxford University Press, Oxford, 146-180.

Rungtusanatham, M., C. Forza, B. R. Koka, F. Salvador, W. Nie. 2005. TQM across multiple countries: Convergence hypothesis versus national specificity arguments. J. Oper. Manag. 23(1): 43-63.

Sapir, E. 1929. The status of linguistics as a science. Language. 207-214.

Saussure, F. 2011. Course in General Linguistics. Columbia University Press, New York, NY.

Schein, E. 1985. Organizational Culture and Leadership. Josey-Bass, San Francisco, CA.

Schleifler, A. 1994. Causal inference. Harvard Business School Publication \#9-894-032.

Shannon, C., W. Weaver. 1949. The Mathematical Theory of Information. University of Illinois Press, Urbana, IL.

Shenkar, O. 2001. Cultural distance revisited: Towards a more rigorous conceptualization and measurement of cultural differences. J. Int. Bus. Stud. 32(3): 519-535. 
Skinner, C. W. 1964. Management of international production. Harv. Bus. Rev. 42(5): 125-136.

Skinner, W. 1969. Manufacturing-missing link in corporate strategy. Harv. Bus. Rev. 47(3): 136.

Sousa, R., C. A. Voss. 2008. Contingency research in operations management practices. J. Oper. Manag. 26(6): 697-713.

Stringfellow, A., M. Teagarden, W. Nie. 2008. Invisible costs in offshoring services work. J. Oper. Manag. 26(2): 164-179.

Szulanski, G. 1996. Exploring internal stickiness: Impediments to the transfer of best practice within the firm. Strateg. Manage. J. 17(1): 27-43.

Szulanski, G. 2000. The process of knowledge transfer: A diachronic analysis of stickiness. Org. Behav. Human Dec. Proc. 82(1): 9-27.

Tung, R. L., A. Verbeke. 2010. Beyond Hofstede and GLOBE: Improving the quality of cross-cultural research. J. Int. Bus. Stud. 41(8): 1259-1274.

Van Wijk, R., J. Jansen, M. Lyles. 2008. Inter- and intra-organizational knowledge transfer: A metaanalytic review and assessment of its antecedents and consequences. J. Manage. Stud. 45(4): 830-853.

Varonis, E. M., S. M. Gass. 1985. Miscommunication in native/ non-native conversation. Lang. Soc. 14(3): 327-343.

Voss, C., K. Blackmon. 1998. Differences in manufacturing strategy decisions between Japanese and Western manufacturing plants: The role of strategic time orientation. J. Oper. Manag. 16: 147158. 
Weber, Y., O. Shenkar, A. Raveh. 1996. National and corporate cultural fit in mergers/acquisitions: An exploratory study. Manage. Sci. 42(8): 1215-1227.

Welch, D., L. Welch. 2008. The importance of language in international knowledge transfer. Manage. Int. Rev. 48(3): 339-360.

Wooldridge, J. 2010. Econometric Analysis of Cross Section and Panel Data, 2nd edn. MIT Press, Cambridge, MA. 